Review

\title{
Collagen at the maternal-fetal interface in human pregnancy
}

Jia-Wei Shi'1,2, Zhen-Zhen Lai², Hui-Li Yang'2, Shao-Liang Yang2, Cheng-Jie Wang², Deng Ao², Lu-Yu Ruan², Hui-Hui Shen ${ }^{2}$, Wen-Jie Zhou ${ }^{3}$, Jie $\mathrm{Mei}^{4}$, Qiang Fu ${ }^{5}$, Ming-Qing Li ${ }^{1,2}$

1. NHC Key Lab of Reproduction Regulation (Shanghai Institute of Planned Parenthood Research), Hospital of Obstetrics and Gynecology, Fudan University, Shanghai 200080, People's Republic of China.

2. Shanghai Key Laboratory of Female Reproductive Endocrine Related Diseases, Hospital of Obstetrics and Gynecology, Fudan University, Shanghai 200080, People's Republic of China.

3. Center of Reproductive Medicine of Ruijin Hospital, Shanghai Jiao Tong University School of Medicine, Shanghai 200025, People's Republic of China.

4. Reproductive Medicine Center, Department of Obstetrics and Gynecology, Nanjing Drum Tower Hospital, The Affiliated Hospital of Nanjing University Medical School, Nanjing, Jiangsu 210008, People's Republic of China.

5. Department of Immunology, Binzhou Medical College, Yantai, 264003, People's Republic of China.

$\bowtie$ Corresponding author: Ming-Qing Li, E-mail: mqli@fudan.edu.cn.

(c) The author(s). This is an open access article distributed under the terms of the Creative Commons Attribution License (https://creativecommons.org/licenses/by/4.0/). See http://ivyspring.com/terms for full terms and conditions.

Received: 2020.03.03; Accepted: 2020.05.15; Published: 2020.05.25

\begin{abstract}
The survival and development of a semi-allogenic fetus during pregnancy require special immune tolerance microenvironment at the maternal fetal interface. During the establishment of a successful pregnancy, the endometrium undergoes a series of changes, and the extracellular matrix (ECM) breaks down and remodels. Collagen is one of the most abundant ECM. Emerging evidence has shown that collagen and its fragment are expressed at the maternal fetal interface. The regulation of expression of collagen is quite complex, and this process involves a multitude of factors. Collagen exerts a critical role during the successful pregnancy. In addition, the abnormal expressions of collagen and its fragments are associated with certain pathological states associated with pregnancy, including recurrent miscarriage, diabetes mellitus with pregnancy, preeclampsia and so on. In this review, the expression and potential roles of collagen under conditions of physiological and pathological pregnancy are systematically discussed.
\end{abstract}

Key words: collagen, NC1 domain, decidua, miscarriage, preeclampsia, diabetes, NK cell, cervix

\section{Introduction}

For a successful pregnancy, the semi-allogenic fetus must not be rejected by the maternal immune system, and the mechanisms that underlie in this process are of critical importance. The cycling endometrium needs extensive tissue remodeling to prepare the embryo for implantation. Some factors expressed at the maternal fetal interface contribute to the successful implantation and pregnancy.

During the establishment of pregnancy, endometrium undergoes rapid growth and differentiation, extracellular matrix (ECM) breaks down and remodels [1]. It is reported that ECM could influence and regulate trophoblast invasion and participate in the remodeling of the decidua at the maternal fetal interface [2,3]. Collagen is the one of the most abundant component of ECM, regulating cellular biological behavior and providing the structural integrity of human tissue [4,5]. Additionally, collagen is widely distributed in various tissues and organs. Its main function is to construct three-dimensional scaffold to maintain tissue integrity and mediate cell adhesion.

To date, the collagen superfamily comprises 29 types in vertebrates, which are formed by at least 46 different polypeptide chains (a chains) [6]. Each collagen is comprised of three a chains with left-handed helix configuration, and the chains are intertwined to form right-handed super helix structure [7]. Collagen is mainly degraded by collagenase, which generally exists in tissue in 
inactive form. Collagen metabolism is related to the expression and activity of matrix metalloproteinase (MMP) [8]. The matrix metalloproteinases (MMPs), a family of zinc-dependent proteases, is able to degrade different components of the ECM and plays a crucial role in the remodeling of various tissues and organs. And the MMP family includes collagenases, stromelysins, matrilysins and other MMPs [8]. MMP-2 and MMP-9 have an important role in endometrial tissue remodeling during pregnancy. They are thought to be playing a crucial role in pregnancy, because they are able to degrade components of the ECM thereby facilitating cell migration and angiogenesis $[8,9]$.

The maternal fetal interface present different types of collagen and corresponding receptors, including collagen type I, III, IV and so on [10]. And the collagen highly expressed at the maternal fetal interface is primarily produced by decidual stromal cells (DSCs) and trophoblasts [11,12]. But the role of collagen in fetus implantation and pregnancy is still not clear enough. In the present review, the expression and the possible function of collagen under conditions of physiological and pathological pregnancy are discussed.

\section{The collagen superfamily}

Collagen is one of the important components of ECM in mammals. To date, the collagen superfamily comprises 29 different members numbered with Roman numerals (I-XXIX) [6]. Obviously, collagen is widely distributed and expressed in different tissues and organs of the body. For each collagen type, it is consisted of three polypeptide chains, called a chains. These three a chains can be either identical to form homotrimers or different to form heterotrimers. The three a chains of collagen are three left-handed polyproline II helices twisted in a right-handed super helix structure [7]. Each distinct a chain is encoded by a different gene. For example, the a chain of collage type IV is encoded by COL4A1, COL4A2, COL4A3, COL4A4, COL4A5 and COL4A6 [13-15]. In addition, it is possible for a single collagen type to have multiple chain compositions, such as collagen type IV can be composed of three distinct heterotrimeric molecules: [(a1(IV)) $)_{2}$ 22(IV)], [a3(IV)a4(IV)a5(IV)] and [(a5(IV) $)_{2}$ a6(IV)] [16]. The collagen molecule is comprised of a triple helical region and two nonhelical regions at both ends of helix [7]. According to the different structure and function, collagen can be divided into different categories, including fibril-forming collagen (e.g., collagen type I and III); basement membrane collagen (e.g., collagen type IV); beaded filament-forming collagen (e.g., collagen type VI); anchoring fibril-forming collagen (e.g., collagen type VI); fiber-associated collagens (e.g., collagen type IX); hexagonal network-forming collagens (e.g., collagen type $\mathrm{X}$ ); transmembrane collagens (e.g., collagen type XIII); and multiplexins (e.g., collagen type XVIII) [17].

Like other proteins, collagen is synthesized on rough endoplasmic reticulum and transported into Golgi apparatus for processing and then secreted to extracellular. The degradation of collagen is mainly associated with the expression and activity of matrix metalloproteinase (MMP), which are able to degrade different components of the ECM [17]. Therefore, MMP plays a crucial role in physiological and pathological processes, such as tissue repair and remodeling, tumor development and metastasis $[18,19]$. Various collagen types are degraded by different MMP. For example, collagen type I, II and III are degraded by MMP-1, MMP-8, MMP-13 and MMP-14. Whereas collagen type IV is preferentially cleaved by MMP-2 and MMP-9 [7].

The basic function of collagen is to maintain the structural integrity of tissues and organs. In addition, collagen plays critical roles in organ development, tissue repair, tumor occurrence and metastasis [20-23]. Collagen plays a series of roles by binding to different receptors. At present, there are four main types of collagen receptor in vertebrates, including integrin, tyrosine kinases receptor, immunoglobulin-like receptor and mannose receptor [7,24]. Furthermore, some of the fragments resulting from the cleavage of collagens are also ligands of integrins [25].

The arrangement of collagen molecules in self-assembled fibers is very important for the biological function of cells attached to them. At the cellular level, the interaction between cells and the surrounding ECM has a critical influence on cell fate and dominates various cell functions. Cells bind to the surrounding ECM through integrin protein, one end of which is bound to the cytoskeleton in cells, the other end has a clear binding site on collagen fibers and other ECM proteins [26]. The increased ECM deposition and protein cross-linking may alter tissue rigidity. Fiber assembly of mature collagen molecules involves intermolecular cross-linking between lysine residues on adjacent collagen molecules. Collagen cross-linking is catalyzed by lysine oxidase and happens between hydroxylated or nonhydroxylated lysine residues in collagen [27]. The cross-linking of collagen will increase the rigidity and mechanical stability of tissue $[28,29]$. In addition, the composition ratio of collagen also affects the rigidity of tissue. The ratio of collagen type I to type III collagen is essential for the functional integrity of various tissues. The increase in the collagen I/III ratio could lead to the increased tissue rigidity. On the contrary, it will 
increase the elasticity of the tissue [30]. This may be due to the different properties and structures of collagen type I and type III. Collagen type I consists of rigid fibers, while collagen type III is considered immature, fragile and elastic [31]. Furthermore, previous studies have also suggested that the rigidity of the collagen modulates cell migration, survival and differentiation [32,33].

\section{The expression of collagen at the maternal fetal interface}

\section{Collagen expression in the trophoblasts}

During the establishment of pregnancy, the embryo implants completely into the uterus surrounded by trophoblasts. The villous trophoblast of the human placenta is the epithelial cover of the fetal chorionic villi floating in maternal blood. As shown in Table 1, several studies have reported on the expression of collagen in trophoblasts. Fu et al observed that the expression of total collagens in the villi in the first trimester with Masson staining. And they also observed collagen type IV expression in trophoblasts by RT-PCR and ELISA [12]. In addition, trophoblasts are able to secret collagen type IV, and even are the main source of collagen type IV [10-12]. And the expressions of collagen type I, III, VI were also detected in villi by immunohistochemistry [10]. Besides the expression of collagen protein, recent studies are also focused on the expression of collagen fragment and receptor in the trophoblasts. As shown in Table 2, the non-collagenous domain 1 (NC1) from a1-3 (IV) and a5 (IV) chain of collagen type IV expressed in the villi. And some villi were devoid of alpha6 (IV) NC1 immunoreactivity while others stained weakly [10]. And the integrin heterodimers $\alpha_{1} \beta_{1}$ and $\alpha_{2} \beta_{1}$ and LAIR-2 are found to be expressed in trophoblasts [10,34,35]. As mentioned above, collagen has many different receptors. Integrin a10, integrin a11, DDR-1 and DDR-2 are all expressed by all trophoblast types [10]. In addition, integrin $\beta 1$ (also known as CD29), a member of integrin family, mediates cell-ECM communication and is also a receptor of collagen [36]. Recent researches also detected the expression of integrin $\beta 1$ in trophoblasts $[37,38]$.

\section{Collagen expression in the decidua}

Decidual tissue is a special tissue stimulated by decidualization inducer to proliferate and differentiate in endometrial stroma, which is very important for the establishment and maintenance of pregnancy [39]. Previous studies showed that collagen type I, III, and V are the main components of ECM in the mouse decidua [40,41]. The expression of total collagens was observed in the human decidua in the first trimester with Masson staining [12]. The expression of collagen type I and III, V, VI were also detected in the decidua $[10,42,43]$. Fu et al observed that collagen type IV expressed in DSCs [12]. Oefner et al observed that the expression of collagen types IV is upregulated at the maternal fetal interface in the first trimester compared to the proliferative and secretory endometrium, especially highly expressed in the decidua [10]. And DSCs could also secret collagen type IV [11,12]. There is also a selective presence of collagen type IV NC1 domains in the decidua. The NC1 domains from a1-3 (IV), a5 (IV) and a6 (IV) chain of collagen type IV express in the decidua, but a4 (IV) NC1 domain is absent with the placental bed [10]. Pollheimer et al showed that both the Collagen type XVIII mRNA and protein express in the first and third trimester decidua, but not in primary trophoblasts [44]. In addition, endostatin is derived from the C-terminal, common $\mathrm{NC1}$ of collagen type XVIII, was also expressed in DSCs at the maternal fetal interface, but absent in all trophoblast subtypes. And their study suggests that DSCs produce endostatin [44]. Arresten and canstatin are also expressed in the decidua [45]. Furthermore, integrin $\beta 1$ as a receptor of collagen is observed to express on the DSCs $[38,46]$.

Table 1. The expression of collagen and its receptor at the human maternal-fetal interface

\begin{tabular}{|c|c|c|c|c|c|}
\hline & \multirow[t]{2}{*}{ Trophoblast } & \multirow[t]{2}{*}{ Decidua } & \multicolumn{3}{|c|}{ Decidual immune cells } \\
\hline & & & NK cell & $\mathrm{T}$ cell & Macrophage \\
\hline Total collagen & $+[11]$ & $+[11]$ & Not mentioned & Not mentioned & Not mentioned \\
\hline Collagen type I & $+[12]$ & $+[12,34]$ & Not mentioned & Not mentioned & Not mentioned \\
\hline Collagen type III & $+[12]$ & $+[12]$ & Not mentioned & Not mentioned & Not mentioned \\
\hline Collagen type IV & $+[10-12]$ & $+[10-12]$ & $+[11]$ & Not mentioned & Not mentioned \\
\hline Collagen type V & Not mentioned & $+[34]$ & Not mentioned & Not mentioned & Not mentioned \\
\hline Collagen type VI & $+[12]$ & $+[12]$ & Not mentioned & Not mentioned & Not mentioned \\
\hline Collagen type XVIII & $-[36]$ & $+[36]$ & Not mentioned & Not mentioned & Not mentioned \\
\hline LAIR-1 & $-[27]$ & Not mentioned & $+[10,11,27]$ & $+[27]$ & $+[27]$ \\
\hline Integrin & $+[12,26,29]$ & $+[30,38]$ & $+[40]$ & $+[41]$ & Not mentioned \\
\hline
\end{tabular}


Table 2. The fragment of collagen at the human maternal-fetal interface

\begin{tabular}{|c|c|c|c|c|c|c|c|c|c|}
\hline & \multicolumn{6}{|c|}{ Collagen type IV NC1 domains } & \multirow[t]{2}{*}{ endostatin } & \multirow[t]{2}{*}{ arresten } & \multirow[t]{2}{*}{ canstatin } \\
\hline & a1 & a2 & a3 & a4 & a5 & a6 & & & \\
\hline Trophoblast & $+[12]$ & & & $-[12]$ & $+[12]$ & $+/-[12]$ & $-[36]$ & Not mentioned & Not mentioned \\
\hline Decidua & & & & & & $+[12]$ & $+[36]$ & $+[37]$ & $+[37]$ \\
\hline
\end{tabular}

\section{Collagen expression on decidual immune cells}

During the normal pregnancy, the numbers of uterine immune cells increase dramatically, and decidual immune cells consist of NK cells $(\sim 70 \%)$, macrophages $(\sim 15 \%)$, T cells $(\sim 15 \%)$, and a very small number of other types of immune cells [47]. The composition of DICs is different from that of peripheral blood. To date, few studies have reported the expression level of collagen on decidual immune cells (DICs) at the maternal fetal interface. A study has reported that decidual NK ( $\mathrm{dNK}$ ) cells can secreted a little of collagen type IV [12]. And it is not clear whether collagen is expressed on the other DICs. But it is worth noting the expression of the collagen receptor on the decidual immune cells.

Leukocyte-associated immunoglobulin like receptors (LAIR) -1 acts as an inhibitory receptor of many types of immune cell, which is also a receptor of collagen. LAIR-1 expresses on the dNK, T-cells and macrophages at the maternal fetal interface $[11,12,35]$. And the expression of LAIR-1 on dNK cell is higher than that on peripheral $\mathrm{NK}(\mathrm{pNK})$ cell [12]. Our previous study has reported that integrin $\beta 1$ is highly expressed on dNK cell. And the expression of integrin $\beta 1$ is higher on $\mathrm{dNK}$ cell than $\mathrm{pNK}$ cell [48]. In addition, the expression of integrin $\beta 1$ is also detected on decidual $\mathrm{T}$ cell [49]. Integrin $\beta 1$ is expressed on the macrophage, but it is not clear whether it is expressed on decidual macrophage [50].

These studies mentioned above may provide us with a new idea, that the collagen plays a series of roles at the maternal fetal interface through interacting with its receptor on DICs, and then contributes to successful pregnancy.

\section{Collagen expression in fetal membranes}

The fetal membranes are not part of the maternal fetal interface, but collagen metabolism in that plays a key role in pregnancy, so we also discussed the expression of collagen in the fetal membranes. Human fetal membranes are composed of the amnion and chorion. The main source of tensile strength of the fetal membranes derives from the collagen contents in the amniotic membrane [51]. The compact layer of the amnion is mainly composed of collagen type I and type III together with small amounts of collagen type IV, V and VI [52,53], whereas collagen type IV and V are the major component of basement membrane of amnion [54-56]. The expression of collagen type IV is also observed in amniotic fluid [57]. Few studies have reported the expression level of collagen in amniotic fluid, although some studies have shown that MMP-9 is expressed in it [58]. Due to the source, quantity and composition of amniotic fluid vary with gestational age and the expression of collagen in amniotic fluid has not been systematically described now.

\section{Regulatory mechanism of collagen expression at the maternal fetal interface}

\section{Pregnancy-associated hormones}

During the pregnancy, placental syncytiotrophoblast and corpus luteum could synthesize a variety of hormones, including estrogen, progesterone, and human chorionic gonadotropin (hCG), which play an important role in maintaining normal pregnancy. Although the specific role of pregnancy associated hormones in regulating collagen expression at the maternal fetal interface is not clear, previous studies have reported that estrogen plays a key role in regulating collagen expression in other organs and tissues. Zhou et al proposed that $17 \beta$-estradiol and progesterone could inhibit the expression and activity of MMP in IL-1 $\beta$ stimulated corneal fibroblasts and thus suppressed the collagen degradation in these cells [59]. Both collagen type I and III expression were increased after treatment with estrogen in vaginal [60]. At present, the research on the regulation of collagen expression by pregnancy-associated hormones in pregnancy mainly focuses on the cervix. Progesterone is able to promote the expression of COL1A1, COL3A1 and COL5A1, whereas estrogen could promote COL3A1 and COL5A1 expression in cervix [61]. In the mouse uterus, the collagen I, III, VI fibrils became thicker and longer after treatment with $17 \beta$-estradiol or progesterone. And the expression of collagen type IV in luminal epithelium basement was reduced after $17 \beta$-estradiol treatment [62]. It worth noting that Collagen type IV expression in the luminal epithelium (LE) basement membrane is much lower than in the vasculature, whereas, in oil-treated ovariectomized uterus, the collagen type IV staining in the LE basement membrane is equally intense as that in the vasculature [62]. As mentioned above, the expression of collagen at the maternal fetal interface is highly in pregnancy. Thus, we speculate that collagen 
expression at the maternal fetal interface is regulated by pregnancy associated hormones. However, it is unclear whether pregnancy associated hormones modulate collagen expression by regulating its synthesis or degradation, and its specific mechanism needs further research.

\section{Hypoxia}

Hypoxia plays a critical role in immunity and inflammation under both physiological and pathological conditions $[63,64]$. During the first trimester of a normal pregnancy, the maternal fetal interface is exposed to a physiological hypoxia microenvironment, due to the extravillous trophoblasts (EVT) invade the spiral arteries, which form an embolism that blocks the spiral arteries and prevents maternal blood into the feto-placental interface $[65,66]$. Hypoxia triggers a profound change in gene transcription, and hypoxia-inducible factor- $1 a$ (HIF-1a) is a transcription factor that widely exists in mammals and human under the condition of hypoxia which is a key factor in response to hypoxia stress [67]. There is no direct report on the relationship between hypoxia microenvironment and collagen expression at the maternal fetal interface. However, it has been reported that collagen is regulated by hypoxia in other tissues or cells. A study has reported that maternal hypoxia significantly increased collagen type I expression in the neonatal heart by western blotting [68]. The expression level of collagen type XV is greatly increased in hypoxia-preconditioned human mesenchymal stromal cells (hMSCs). And HIF-1a activity might play a role in collagen type XV transcriptional activation in hMSCs [69]. The expression of collagen type I and HIF-1a both increase in hepatic stellate cells (HSCs) under the condition of hypoxia [70,71]. COL1A1 and COL3A1 protein expressions are increased in hypoxia HSCs compared to normoxia group. And the expression of HIF-1a is also increased. Importantly, the deposition and secretion of COL1A1 and COL3A1 are decreased by silencing HIF-1a expression [72]. To sum up, under the condition of hypoxia, there may be an increase of HIF-1a expression, thus promoting the expression of collagen. In addition, some diseases occur during pregnancy may lead to the changes of hemodynamic parameters of placental bed artery. And abnormal blood flow in the intervillus is able to affect the diffusing function of the placental barrier, and then create a state of hypoxia. Ortega et al found that the increased presence of collagen type III in the placenta of women with venous insufficiency compared to normal group [73]. This result suggests that the expression of collage $0 \mathrm{n} 0 \ldots$ increase here may be a mechanism triggered by a possible hypoxia state caused by altered blood flow in the placenta in patients with venous insufficiency during pregnancy. To date, there is insufficient experimental evidence to prove that collagen expression at the maternal fetal interface is directly regulated by hypoxia, but it is known that the maternal-fetal itself is a hypoxic microenvironment, and the expression of some collagen is increased during pregnancy. Therefore, we speculate that the hypoxia microenvironment at the maternal fetal interface may be able to promote the expression of collagen.

\section{The role of collagen in normal pregnancy}

\section{Trophoblast invasion}

Trophoblasts exert a critical role in normal pregnancy. Their proliferative, invasion, and apoptotic properties are modulated by a series of factors, including cytokines, chemokines, ECM and so on $[74,75]$. As mentioned above, the expression of collagen and its fragment could be observed at the maternal fetal interface. However, the effect of collagen protein and collagen fragments seems to be the opposite. Traditionally, the collagen has been thought of primarily as a three-dimensional scaffold that binds cells and tissues together [76]. However, collagen also is able to regulate the biological behavior of cells. Collagen protein plays a critical role in enhancing the adhesion, proliferation and invasion of cell [77-79]. Collagen has an important role in trophoblast adhesion at the maternal fetal interface. It was observed that trophoblast adhesiveness was highest in the presence to collagen type I and collagen type IV compared with other ECM [80]. Collagen type I enhances carcinoma cell migration in vitro [81]. And collagen type XVII could promote less aggressive squamous cell carcinoma cells invasion [82]. However, some of the NC1 domain of collagen seem to have the ability to inhibit angiogenesis, cell proliferation and invasion.[30] Recent studies have reported that endostatin which is the $\mathrm{NC1}$ domain of collagen type XVIII could restrict the development of tumor by inhibit the proliferation, invasion of cell $[83,84]$. The a6 (IV) and a4 (IV) domain of collagen type IV exert an anti-tumor activity by decreasing proliferative and invasive properties of tumor cell [85]. At present, there are not enough studies reported on the role of collagen and its fragments in pregnancy. It is worth noting that collagen and its fragments are both expressed at the maternal fetal interface, although their expression levels are not consistent. Trophoblast could cleave endostatin and endostatinlike fragments from $\mathrm{NC1}$ domain of collagen type XVIII by producing proteases [86]. Recombinant endostatin reduces trophoblast invasion in vitro [86]. 
A previous study has suggested endostatin upregulates MMP-2 expression in trophoblasts in order to modulate trophoblast invasiveness [44]. Pollheimer et al proposed that invasive trophoblasts may produce the inhibitory protein as encountering stromal cells of the decidua basalis [86]. In addition, EVT expresses integrin av $\beta 3$, which can bind to a2 (IV) and a3 (IV) NC1 domains [87,88]. These results suggest that NC1 domain of collagen type IV may have a direct interaction with trophoblast. So we speculate that the a (IV) NC1 domain of collagen type IV which is selectively expressed at the maternal fetal interface may similarly influence MMP expression by EVT, and then regulate the invasion of trophoblast. Furthermore, integrin $\beta 1$ participates in the trophoblast invasion, but whether collagen is involved in this process has not been confirmed yet $[37,38]$.

The degradation and remodeling of collagen in the uterus in mice during the peri-implantation should be given attention. In the preimplantation period, collagen type I, III, IV and VI were observed throughout the uterine endometrium and decidua. During the peri-implantation, the expression of collagen type I, III, VI disappear from the decidua upon embryo. Whereas, collagen type IV accumulates in the decidua, and also expressed highly in embryonic basement membranes [62].

During the establishment of pregnancy, placentation involves in the invasion of decidua basalis and the inner third of the myometrium by
EVT. It is known that this process requires trophoblast pass through ECM and remodeling of ECM. Collagen as an important component of ECM, which is highly expressed at the maternal-fetal interface, must undergo remodeling during trophoblast invasion [89]. Based on the current research, we speculate that, as shown in Figure 1, integrin expressed by trophoblast combines with collagen expressed at the maternal fetal interface to promote trophoblast adhesion. The trophoblast then invades into decidual tissue, which is accompanied by collagen degradation and remodeling. The degradation of collagen produces different fragments, which in turn inhibit the invasion of trophoblasts, thus achieving a delicate balance.

\section{Immune tolerance}

Pregnancy is an immune paradox in which the semi-allogenic fetus must not be rejected by the maternal immune system [90]. The mechanisms that underlie in forming immune tolerance microenvironment are of critical importance, some factors expressed at the maternal fetal interface contribute to the immune tolerance, such as collagen. Previous study has reported that collagen has potent immunomodulatory properties in autoimmune and tumor diseases [91,92]. The forming and maintenance of immune tolerance at the maternal fetal interface are accompanied by special $\mathrm{dNK}$ cells function, $\mathrm{T}$ helper cell 2 (Th2) bias and macrophage polarization.

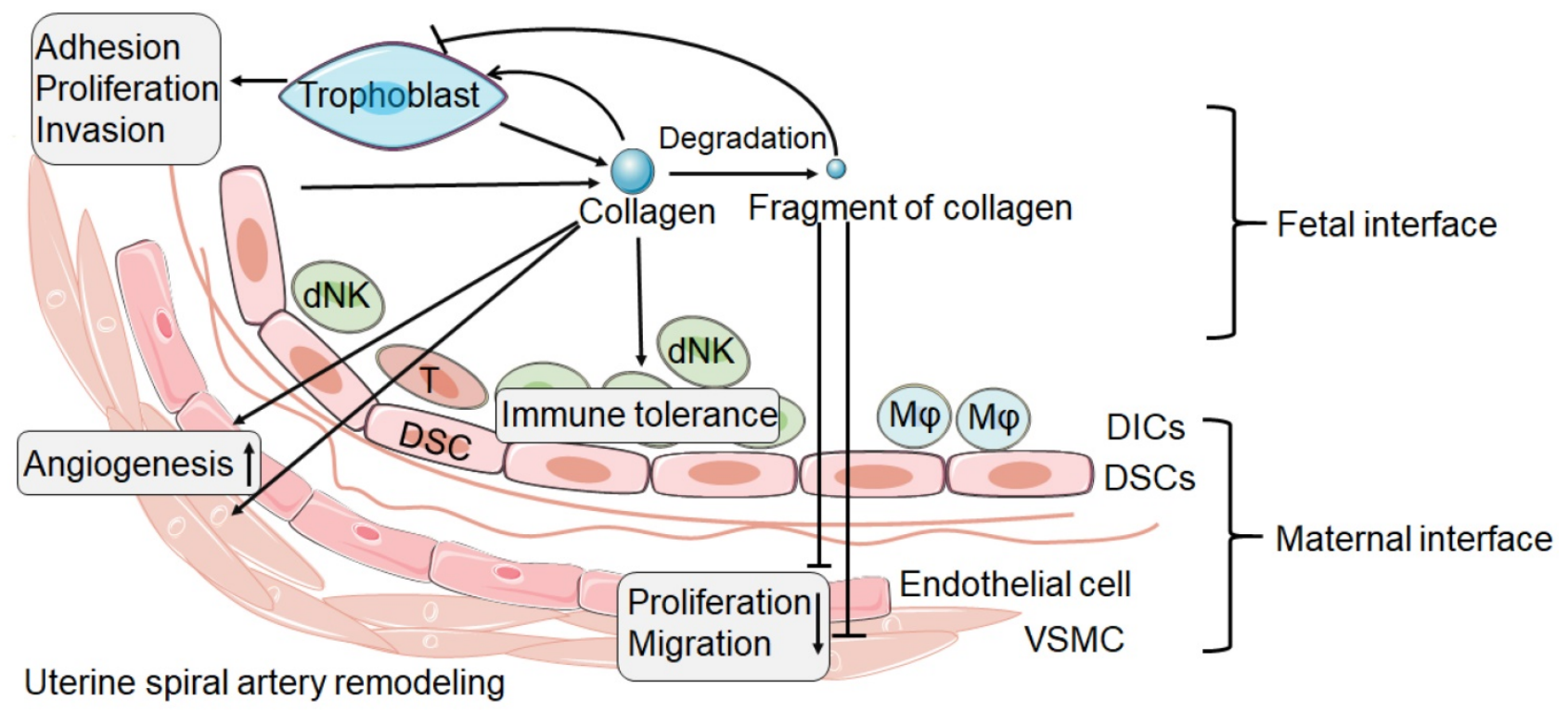

Figure 1. The possible role of collagen and its fragment at the maternal fetal interface. The collagen at the maternal fetal interface is mainly produced by trophoblast and decidual stromal cell (DSC). Collagen might play an important role in the trophoblast adhesion, proliferation and invasion. But the process of trophoblast invasion is accompanied by collagen degradation and remodeling, and then produces a number of collagen fragments. The fragment of collagen might be able to inhibit the trophoblast invasion. In addition, collagen and its fragment seem to have the opposite effect in spiral artery remodeling. Collagen may promote the spiral artery remodeling. However, the fragment of collagen seems to be able to inhibit the proliferation and migration of vascular smooth muscle cell (VSMC) and endothelial cell. In addition, collagen promotes immune tolerance of decidual immune cells (DICs). dNK: decidual natural killer cell; T: T cell; M $\varphi$ : macrophage. 


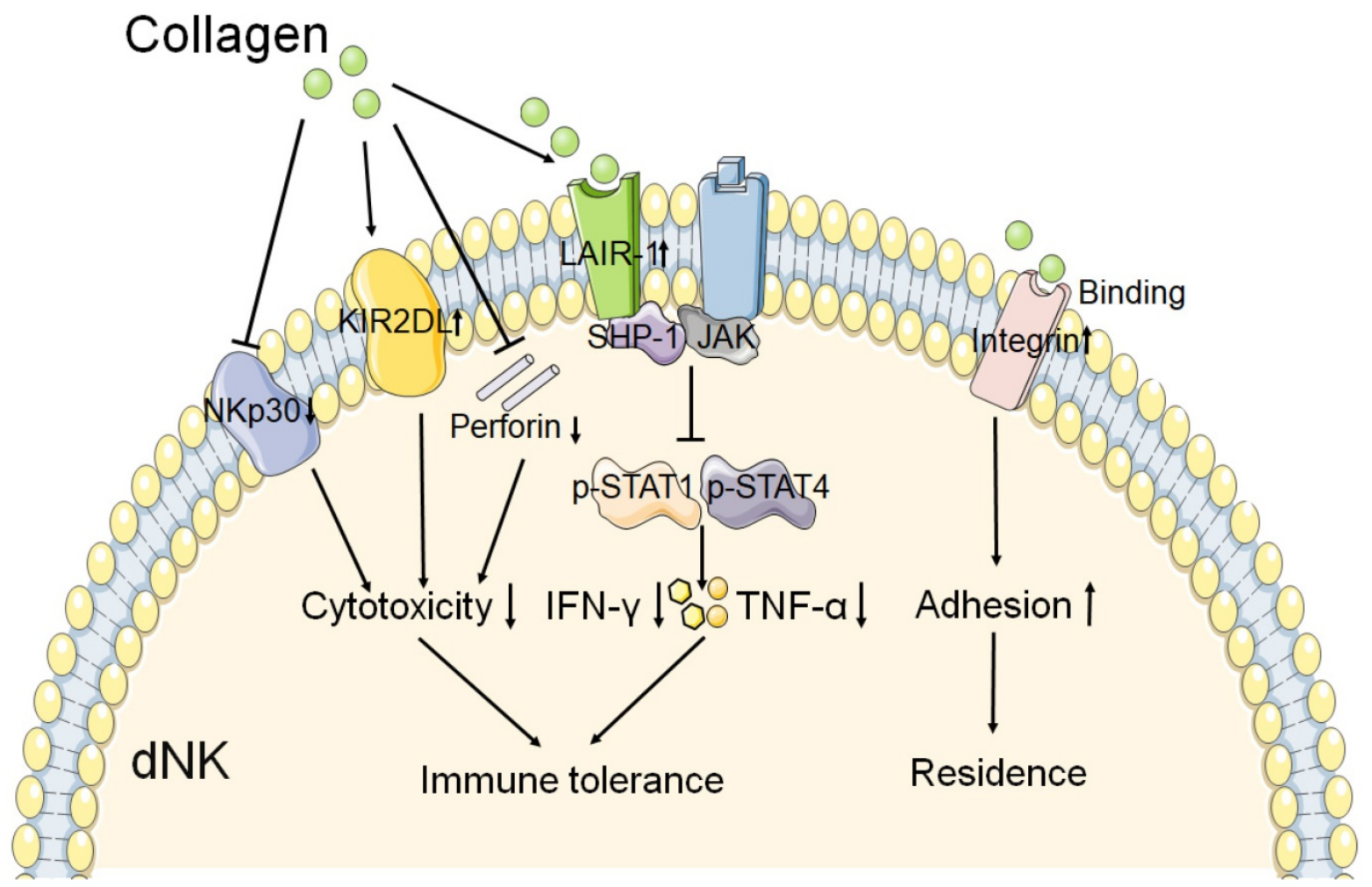

Figure 2. The role of collagen in the function of dNK cell. The interaction of collagen with integrin $\beta 1$ may promote the adhesion of dNK cell, and then contribute to the residence of NK cell in decidua. And collagen binds to the LAIR-1 which is expressed on dNK cell, triggers the SHP-1 binding to JAK1 and JAK2 in dNK cell. Resulting in the phosphorylation of STATI and STAT4 reduction, and then the production of IFN- $y$ and TNF- $\alpha$ is decreased. In addition, collagen could reduce the cytotoxicity receptor NKp30 expression, and increase the inhibitory receptor KIR2DL1 expression on dNK cell. The production of perforin is also decreased by collagen. These results mentioned above leads to decreased cytotoxicity and activity of dNK cell. Therefore, collagen plays a key role in the function of dNK cell, and then contributes to the immune tolerance at the maternal fetal interface.

As mentioned above, the numbers of DICs increase dramatically during decidualization, and the composition of DICs is different from the leukocytes in the peripheral blood. It is believed that changes in the DCIs are partly due to the recruitment of peripheral immune cells, and partly due to the resident population of endometrium $[93,94]$. Previous studies have reported that chemokine could regulate the recruitment of DICs. Besides the recruitment of immune cells, the residence of DICs is also very important for maintaining immune tolerance during normal pregnancy. It is reported that integrin $\beta 1$ is important for the adhesive ability of dNK cells to DSCs [48]. Due to the DSC is observed to highly express collagen, and collagen could regulate the adhesion by integrin $\beta 1$ in other cells, collagen is supposed to be involved in the adhesion between dNK and DSC [95]. Thus, we proposed that collagen expressed at the maternal fetal interface is important for NK cell residence by integrating with integrin expressed on dNK cells.

A study has reported that collagen could decrease the expression of NKp30 on dNKs, one of the natural cytotoxicity receptors, and perforin [12]. This result suggests that collagen might contribute to the decreased cytotoxicity of $\mathrm{dNK}$ at the maternal fetal interface. The expression of inhibitory receptor KIR2DL1 on dNKs was increased after treatment with increasing concentrations of collagen [12]. Fu and his team observed that trophoblasts and DSCs could regulate the expression of IFN- $\gamma$ and TNF- $\alpha$ in $d N K$ cells through collagen. And the results of western blot show that collagen could upregulate the expression of LAIR-1, decreased the expression of both p-STAT1 and p-STAT4 in dNK cells [11]. So they proposed that collagen which produced by DSCs and trophoblasts induced LAIR-1 expression. And then interaction between collagen and LAIR-1 triggers the binding of SHP-1 to JAK1 and JAK2 in dNK cells, and this leads to downregulation of the phosphorylation of STAT1 and STAT4 [11]. As a result, the production of IFN- $\gamma$ and TNF-a is inhibited, which contributes to the immune tolerance at the maternal fetal interface. As shown in Figure 2, these results mentioned above suggest that collagen play a key role in immune tolerance by regulation the function of $\mathrm{dNK}$ cells during normal pregnancy.

There is no direct report on the role of collagen in regulating $\mathrm{T}$ cell differentiation and macrophage polarization at the maternal fetal interface. However, as mentioned above, integrin $\beta 1$ and inhibitory receptor LAIR-1 express on the decidual T-cells and 
macrophages at the maternal fetal interface $[11,12,35,49]$. And recent research suggested that collagen type II is able to induce peripheral tolerance in $B A L B / C$ mice by generating $C D 8^{+} \mathrm{T}$ regulatory (Treg) cells [96]. Polymerized-type I collagen has been shown to exert downregulation of autoimmune inflammation by regulating both Treg/Th17 differentiation and Th1/Th2 balance [97]. During the development of collagen-induced arthritis, the collagen-specific $\mathrm{CD}^{+} \mathrm{T}$ cell response shifts in vivo from a dominant Th0/Th1 response to a clear Th2 phenotype [98]. Therefore, collagen may play a key role in $\mathrm{T}$ cell differentiation at the maternal fetal interface.

In addition, previous studies have suggested that decidual macrophages, which play a critical role in the endometrium during normal pregnancy, are more closely associated with the M2 phenotype $[99,100]$. Chen et al observed that lack of collagen type VI in Col6al-/-mice increased polarization toward the M1 phenotype, and reduced polarization toward the M2 phenotype [101]. In addition, Lv et al observed that collagen type VI within the nerve conduit could induce polarized macrophage toward the M2 phenotype, and then promote nerve regeneration and functional recovery [102]. These results suggest that collagen is able to induce the polarization of M2 in other tissues, which provides the possibility for the future study of collagen promoting the differentiation of macrophages into M2 phenotype at the maternal fetal interface.

In conclusion, the high expression of collagen at the maternal fetal interface may induce the immune tolerance microenvironment by regulating the differentiation and function of immune cells in decidua, which is conducive to successful implantation and pregnancy.

\section{Angiogenesis}

Angiogenesis is a key process during a successful pregnancy, which is involved in decidualization, implantation, and embryo growth [103]. During the process of angiogenesis, ECM remodeling is particularly important for the development of new blood vessels. Collagen, as the primary constituent of the ECM, requires active degradation and remodeling as endothelial cells proliferation, migration and differentiation, in order to form new vascular networks. The current research is mainly based on collagen as a three-dimensional scaffold to support angiogenesis [104-106]. Previous study has suggested that collagen type VI began to clear in the decidua during implantation [62]. Interestingly, the degradation of collagen type VI in the decidual does not extend to the vessel walls
$[62,107]$. It probably suggests that collagen which envelops vessels could integrate them into the three-dimensional tissue architecture in order to vascular remodeling. In addition, the fragment of collagen seems to have the ability to inhibit angiogenesis. Three separate a-chain trimers exist for type IV collagen: [(a1(IV)) $\left.{ }_{2} \mathrm{a} 2(\mathrm{IV})\right]$, [a3(IV)a4(IV) a5(IV)] and [(a5(IV) $\left.)_{2} a 6(I V)\right]$. Since collagen type IV consists of six different a chains, the degradation of collagen type IV can potentially give rise to a vast array of fragments. Some of the NC1 fragments of collagen type IV have anti-angiogenic effects that decrease endothelial cell proliferation, migration and tube formation, as well as increase endothelial cell apoptosis, including arresten (COL4A1), canstatin (COL4A2) and tumstatin (COL4A3) [30,108-110]. Previous study reported that overexpression of arresten in vascular smooth muscle cells (VSMC) could reduce VSMC proliferation [111]. VSMC also play a critical role in spiral artery remodeling process in pregnancy. Therefore, the NC1 fragment of collagen may be involved in regulating the physiological remodeling of maternal spiral arteries. In addition, as mentioned above, endostatin expression was observed at the maternal fetal interface. The role of endostatin in uterine spiral artery remodeling has not been reported. But endostatin can reduce endothelial cell migration, proliferation, and then inhibit vascular angiogenesis in other tissues [112-115]. Based on the current research, it can be concluded that the collagen and its fragments expressed at the maternal fetal interface may be able to regulate the remodeling of spiral arteries, and collagen metabolism may also be closely related to vascular remodeling.

In summary, we speculate that the collagen expressed at the maternal fetal interface may play a role in promoting trophoblast invasion and angiogenesis. MMP selectively degrade collagen and produce fragments which may exert to inhibit cell adhesion, proliferation and invasion, as well as have anti angiogenic effect. There is a delicate balance between the expression of collagen protein and collagen fragments, which contributes to successful pregnancy.

\section{Cervical remodeling}

Cervical remodeling is accompanied by extensive collagen metabolism, which is essential for successful pregnancy. During normal pregnancy, the cervix keeps closed and firm in order to prevent passage of an immature infant through the birth canal. On the contrary, at term, the cervix must become soft and open sufficiently to allow delivery of the full-term fetus. The cervix stroma is mainly 
composed of fibroblasts, followed by smooth muscle cells [116]. These cells can secret a series of ECM, including collagen fiber, elastin and so on. During pregnancy, cervical remodeling is the process of a series of physiological changes in the cervix, which can be divided into four stages: softening, ripening, dilation and postpartum repair, all of which are accompanied by ECM remodeling [117]. Collagen type I and III are the main components responsible for mechanical strength in the cervix $[27,116]$. Due to the limitations of human in vivo experiments, research of cervical remodeling in pregnancy is mainly from rodent experiments. The expression of collagen type I in the cervix during the first half of pregnancy was similar to the nonpregnant mice, but significantly increased in the latter days of gestation. And then levels declined to nonpregnant group by 24 hours postpartum [27]. Previous studies have demonstrated that the cervical softening is characterized by an increase in the solubility of collagen and no change in the total collagen content [117]. That is to say, the decrease of collagen cross-linking forming enzyme leads to the decrease of cross-links between collagen molecules, and then reduces the mechanical strength of cervical tissue [27,118]. Unlike cervical softening, the ripening process is very rapid, during which the compliance of the cervix increases and the cervix is easy to dilate. At this stage, the diameter of cervical collagen fibrils gradually increases, and the distance between fibers also increases [118]. In addition, the characteristics of this stage also include the transition from long and thin collagen fibers to thick and curved fibers in the cervix [118]. These changes enable the cervix to maximize its compliance and thus facilitate cervical dilatation. The causes of spontaneous preterm birth are very complex. One of the reasons is that cervical softening, shortening and dilation caused by early cervical remodeling can lead to spontaneous preterm birth. Progesterone treatment could reduce the risk of premature birth $[119,120]$. Prepartum cervical ripening is closely related to collagen remodeling in cervix. Progesterone withdrawal could reduce the abundance of collagen fibers in the cervix, and promote the cervical remodeling in nonpregnant mice [121]. Steven et al reported that the density and structure of collagen in cervix were enhanced by treatment with progesterone [122]. It has been reported that the progesterone receptor proteins in the cervix of women prior to parturition decreased significantly [52]. These results suggest that the concentration of progesterone is associated with collagen remodeling in cervix. Progesterone treatment may reduce the occurrence of premature birth through delaying cervical remodeling.

\section{The role of collagen in pathological pregnancy}

\section{Recurrent miscarriage}

Recurrent miscarriage (RM), also known as spontaneous abortion, refers to the experience of at least two or three spontaneous miscarriages before the 24th gestational week. Chromosome and endocrine abnormalities, anatomical defects, acquired infection, and immunological factors are understood to be the major cause of RM [123,124]. The cause of RM remains unexplained in almost half of patients. A series of studies have shown that the abnormal expression of collagen and its fragments at the maternal fetal interface may be associated with unexplained recurrent miscarriage. The staining of total collagens in the villi and decidua is weaker in miscarriage compared with normal pregnancy by using Masson staining [12]. Decreased expression of collagen is observed in decidual tissue of patients who undergo $\mathrm{RM}$, including collage type IV and collagen type V $[11,12,42,43]$. Although the a chains of collagen type I and III were almost similar in the decidua obtained from normal pregnancy and RM, those of a1 (V) and $\mathrm{a} 2(\mathrm{~V})$ were markedly decreased in the decidua from RM [42]. In addition, the mRNA and protein secretion of collagen type IV in trophoblasts and DSCs from miscarriage were lower than those of normal pregnancy [12]. It is not clear whether the abnormal expression of collagen is the cause or the result of miscarriage. But as mentioned above, collagen has an important role in inducing immune tolerance at the maternal fetal interface. And there is also abnormal expression of collagen at the maternal fetal interface. In addition, the expression of LAIR- 1 on dNK cells from miscarriage was decreased compared with that of the normal pregnancy [12]. However, the expression level of integrin $\beta 1$ is higher on dNK cells from RM than those from women with normal pregnancy [48]. This result suggests that the dNK cells form RM have stronger adhesive capacity. But the relationship between abnormal expression of integrin $\beta 1$ and the development of RM has not been revealed. Based on the studies mentioned above, we speculate that the abnormal expression of collagen at the maternal fetal interface may not fully form the immune tolerance microenvironment, leading to miscarriage. Future research can focus on the role of collagen at the maternal fetal interface immune microenvironment, so as to provide a new target for RM treatment.

\section{Diabetes mellitus with pregnancy}

There are two conditions of diabetes occur during pregnancy, one is diabetes mellitus with 
pregnancy, and another is gestational diabetes. Compared with women who do not have diabetes mellitus, those with pre-existing diabetes mellitus have an increased risk of pregnancy complications. Previous researches reported impaired decidualization in diabetic mouse $[125,126]$. Dixon et al observed in the diabetic nephropathy, the expression levels of collagen types IV and V increase compared to normal people, whereas collagen types I and III appear at advanced stages of the disease [127]. Favaro and his team established a mouse model of long-term type 1 diabetes specifically delineated to reproductive investigations. The model mouse has impaired decidua and less implantations compared to the control group. And they found that the deposition collagen increased in the decidua in the model group compared to the control group. In addition, they analyzed the contribution of specific collagen types through immunohistochemistry. Diabetes increased the proportion of collagen types I and V, whereas decreased collagen type III deposition. And in the expression level of mRNA, only COL1A1 mRNA levels significantly increased in the diabetic group decidua [126]. Above results indicate that collagen composition at the maternal fetal interface is mainly regulated by post transcriptional mechanisms in the diabetic pregnancy. The defect of decidualization is related to the abnormal deposition of type III collagen [128]. Therefore, depended on the researches mentioned above, impaired decidualization by diabetes might be associated with abnormal expression of collagen at the maternal fetal interface during early embryonic development.

\section{Preeclampsia}

Preeclampsia is a serious complication of pregnancy manifested as maternal hypertension in pregnancy (HTN-Preg) and fetal growth restriction, and also a major contributor to maternal and perinatal morbidity and mortality worldwide [129]. Inadequate placentation and placental ischemia could be initiating events of the occurrence of preeclampsia. Placental ischemia might be an important factor leads to abnormal vascular remodeling at the maternal fetal interface. Placental ischemia, possibly through the production of TNF- $\alpha$, contributes to the increasing levels of MMP-1 and MMP-7, which, in turn, alter collagen deposition and cause inadequate tissue remodeling in HTN-Preg [130]. In turn, the over deposition of collagen may lead to inadequate vascular remodeling at the maternal fetal interface, resulting in pregnancy-induced hypertension and even preeclampsia. Lin et al observed that the collagen type IV immunoreactive bands were enhanced in uterus and uterine artery of reduced uterine perfusion pressure (RUPP) compared to pregnant rats [9]. Compared with normal pregnant rats, the MMP-2 and MMP-9 levels in the aorta, uterus and placenta of RUPP rats decreased, suggesting that low MMP levels may lead to excessive collagen deposition, affect smooth muscle growth, and decrease the remodeling of spiral arteries [131]. Therefore, the abnormal expression of MMP may lead to the over deposition of collagen, which may affect the remodeling of uterine spiral artery, and it may be an important factor in the pathogenesis of preeclampsia.

In addition, there is abnormal expression of collagen fragments in preeclampsia. As mentioned above, the polypeptide chains of Collagen type IV are encoded by six genes, including COL4A1, COL4A2, COL4A3, COL4A4, COL4A5 and COL4A6. A study identified that COL4A1 and COL4A2 as maternal preeclampsia susceptibility genes, which code for collagen type IV a chain 1 and a chain 2 [132]. And the mRNA expressions of these genes are significantly increased in preeclampsia decidua [133]. As mentioned above, arresten is considered to be an anti-angiogenic factor. Additionally, Yong et al. demonstrated that the expression of arresten fragments were significantly increased in plasma during the second and third trimester in the preeclampsia compared with normotensive. The increase in arresten during the third trimester correlated with the requirement for magnesium sulphate treatment. In addition, decidual levels of arresten monomer were also increased in the third trimester [133]. The role of abnormally expression of arresten in the pathogenesis of preeclampsia is not clear. But previous study reported that arresten on primary vascular smooth muscle cells (VSMC) by transfecting the cells with the arresten gene, could reduce VSMC proliferation [111]. And VSMC plays a critical role in spiral artery remodeling process in pregnancy. Therefore, arresten, which is the NC1 fragment of collagen type IV, may be involved in regulating the function of VSMC, and then mediating the occurrence of preeclampsia. Based on the above study, we speculate that the over deposition of collagen and some fragments of collagen may be related to the insufficient remodeling of uterine spiral artery at the maternal fetal interface.

Human placenta is an important organ for fetal growth and development, which consists of the basal decidua of the maternal components and chorionic villi of the fetus. Previous studies suggest that fibrosis in the villous stroma of preeclampsia placentas is associated with ischemia and hypoxia $[134,135]$. During early placental development, the invasion of extravillous trophoblast into placental bed is 
insufficient, which leads to the dysfunction of uterine spiral artery remodeling. In turn, this causes the decrease of perfusion of intervillous space. In this ischemic and anoxic environment, villi undergo a series of changes, such as collagen deposition [134]. Fibrosis of villous stroma is one of the most prominent features of preeclampsia, which refers to the excessive deposition of ECM in the connective tissue [134]. As mentioned above, the abnormal expression of collagen in placenta tissue could be observed in the patients of preeclampsia. And the level of COL1A1 is higher in the fibroblasts from preeclampsia than those from normal placentas [136]. Placental fibroblasts could increase the production of collagen type I and IV in hypoxic conditions in vitro $[64,136]$. A previous study suggests that due to ischemia and hypoxia, transforming growth factor $\beta 1$ (TGF $\beta 1$ ) signal is activated in fibroblasts of preeclampsia placenta, which may lead to the over production of collagen, and then contributes to placenta fibrosis [136].

In conclusion, in the placenta of preeclampsia patients, the over-activation of fibroblasts and the decrease of MMP expression lead to the abnormal deposition of collagen at the maternal fetal interface, and promote placental fibrosis. In turn, excessive deposition of collagen will lead to the insufficient remodeling of uterine spiral artery, and aggravate the progress of preeclampsia.

\section{Premature rupture of membranes}

The rupture of fetal membranes is a crucial event in parturition, accompanied with extensive degradation of collagen. Premature rupture of membranes (PROM) refers to the spontaneous rupture of fetal membranes before delivery. Full-term PROM refers to the premature rupture of membranes occurring in woman after 37 weeks of pregnancy. Preterm premature rupture of membranes (pPROM) accounts for about one third of preterm birth [116]. The physical integrity of the fetal membranes is required to be maintained until term delivery in normal pregnancy. The animal model has demonstrated that the amnion undergoes collagen remodeling as gestation progress [137]. Previous studies indicate that with advancing gestational age, the abundance of collagen in the fetal membranes decreases $[138,139]$. COL1A1 and COL1A2, the two subunits of collagen type I, which is one of the major collagen types that determine the tensile strength of the amnion, are significantly decreased in the vaginal delivery with amnion tissues of spontaneous rupture of membranes as compared with the amnion tissues from pregnancies after elective cesarean section without rupture of membranes and labor [140]. Zuo et al reported that the expression of collagen type IV in full-term PROM patients in fetal membranes was significantly less than the control group. And they also observed that serum collagen type IV in full-term PROM patients was lower, whereas serum and amniotic fluid MMP-9 were higher than control group [58]. It is known that collagen type IV is one of the main substrates of MMP-2 and MMP-9. Thus, the authors suggested that the serum increased serum MMP-9 induced the degradation of collagen type IV, and thus led to the PROM [58]. And detection of MMP and collagen expression in serum may be able to predict the risk of PROM in pregnant women in advance. Theoretically, the increase of MMP-9 in amniotic fluid of pregnant women with PROM will result in the decrease of collagen type IV in amniotic fluid. However, unexpectedly, the collagen type IV of amniotic fluid in full-term PROM patients was significantly higher than that of the control group [58]. This result suggests that except for MMPs, collagen type IV may be regulated by other factors. Previous study has demonstrated that the activity of MMP-2 and MMP-9 in amnion increased with gestational age [141]. The expression and activity of MMP-2 and MMP-9 in the fetal membranes is increased markedly in labor compared with nonlabor, whether in term or preterm $[139,141]$. In addition, the abundance and activity of MMP-7 in the amniotic fluid and amnion tissue increased with the increase of gestational age and further increased in preterm labor [142,143]. Collagen type IV is the major component comprising the basement membrane in the amnion, and also is the most important substrate of MMP-7. Maymon et al suggests that the abundance of MMP-7 in the amniotic fluid is increased with the increase of gestational age and further increased in preterm labor [142]. Wang et al observed that the expression of MMP-7 was increased, whereas COL4A5 was decreased significantly in the amnion tissue collected from vaginal deliveries with spontaneous rupture of membranes compared with that collected from elective Caesarean sections without labor [144]. This data suggests that collagen degradation by MMP leads to the weakening of the strength of the fetal membrane, and consequently results to the rupture of the fetal membranes. The degradation of collagen can occur either extracellularly through degradation by MMPs or intracellularly via autophagic and proteasomic pathways in the process of membrane rupture. Cortisol regenerating enzyme $11 \beta$-hydroxysteroid dehydrogenase 1 (11 $\beta$-HSD1) is expressed in almost all cell types of fetal membranes, and its expression increases with the advancing of gestational age $[145,146]$. This result can explain the increase of cortisol abundance in fetal membranes in 
the last trimester. Cortisol regenerated by $11 \beta-\mathrm{HSD} 1$ in amniotic fibroblasts is able to reduce the abundance of collagen type III by ubiquitin proteasome pathway [52]. And collagen type I could be degraded by cortisol through lysosome-mediated autophagy in amnion fibroblasts [147]. These results suggest that cortisol mediated degradation of amniotic collagen may play an important role in fetal membranes rupture.

Additionally, the MMP/TIMP imbalance is also involved in the fetal membranes rupture. Tissue inhibitor of metalloproteinase (TIMPs) is an endogenous secretory protein, which is a specific inhibitor of MMPs. TIMPs can bind with zinc ion in the corresponding catalytic activity center of MMP and block its catalytic activity. TIMPs are thought to regulate degradation of basement membrane and ECM by MMPs during tissue remodeling. Previous reports have observed the presence of TIMP-1, TIMP-2, TIMP-3 and TIMP-4 in fetal membranes collected from women undergoing normal labor as well as nonlaboring women [148]. The level of TIMP-1 in amniotic fluid in pPROM group is higher compared with women with preterm and term labor with intact membranes and undergoing Cesarean sections, whereas the expression of TIMP-2 decreased in pPROM [54,140]. Similarly, a study also suggests that the concentration of TIMP-2 in amniotic fluid increases with gestational age but decreases in the context of term and preterm labor, rupture of membranes and intrauterine infection [149]. These results suggest that the increase of TIMP-2 concentration in amniotic cavity may help to protect amniotic membrane from excessive MMP activity generated during the process of uterine distention. And when in labor, the decrease of TIMP-2 relieved the inhibition of MMP activity, contributing to the rupture of fetal membrane. Previous studies have reported that the expression of MMP and TIMP is regulated by microbial infection in other tissues $[150,151]$. Maymon et al found that amniotic fluid TIMP-2 concentrations were significantly lower in women with intraamniotic infection than in those without infection, whereas infection did not increase amniotic fluid MMP-2 concentrations. But another report showed that the expression of MMP-2 and MMP-9 in the fetal membranes was increased after exposure to Escherichia coli, while the secretion of TIMP-1, TIMP-2, and TIMP-4 remained without significant changes. At the same time, the collagen content was significantly decreased in infected membranes [152]. These results indicate that the expression of MMP/TIMP is regulated by pathogenic microorganisms, but different pathogens may affect different types of MMP/TIMP. And the abnormal expression of MMP/TIMP in amniotic fluid may indicate the presence of intraamniotic infection. Infection will affect the balance of MMP/TIMP in amniotic fluid or fetal membrane, which will lead to the degradation of collagen and rupture of fetal membrane, ultimately affect the outcome of pregnancy.

\section{Conclusions and perspectives}

Collagen is one of the most abundant proteins of the ECM. Numerous studies have reported on its role in tumor. However, in recent years, its specific role at the maternal fetal interface has also attracted increasing levels of attention. Some of the collagen protein and its fragments are expressed at the maternal fetal interface, and fulfill a series of roles through interacting with their receptors. On the one hand, collagen might have the ability to regulate the trophoblast proliferation and invasion, and even angiogenesis. On the other hand, collagen exerts important roles in inducing immune tolerance at the maternal fetal interface. In addition, there are abnormal expression levels of collagen in pathological pregnancy. Therefore, at the maternal fetal interface, the normal expression of collagen may be essential for successful pregnancy. However, the mechanism of collagen action at the maternal fetal interface is not clear enough. For one thing, there is a great variety of collagen, and its degradation can also produce numerous fragments. Furthermore, the research on collagen at the maternal fetal interface is limited to some types at present. For another thing, it seems that the effect of collagen and its fragments is not consistent. Furthermore, collagen at the maternal fetal interface is constantly degraded and remolded during the establishment of pregnancy. Thus, regulating the expression and metabolism of collagen may be a potential target for clinical treatment of patients with abnormal pregnancy, although further researches are required to confirm it.

\section{Acknowledgements}

\section{Funding}

This study supported by the National Natural Science Foundation of China (NSFC) (No. 31970798, 31671200, 81901563, 81601354 and 81571512), the National Key Research and Development Program of China (2017YFC1001404), the Innovation-oriented Science and Technology Grant from NPFPC Key Laboratory of Reproduction Regulation (CX2017-2), the Program for Zhuoxue of Fudan University, and the Shanghai Sailing Program (19YF1438500). 


\section{Authors' contributions}

J.W.S performed the literature research, wrote the manuscript and prepared the table and figures. Z.Z.L, H.L.Y., S.L.Y., C.J.W, D.A., L.Y.R., H.H.S., W.J.Z., J.M., and Q.F. helped to perform revisions and critically discussed the complete manuscript. M.Q.L. designed and wrote the manuscript, supervised, and critically reviewed the complete manuscript. All authors have approved it for publication.

\section{Competing Interests}

The authors have declared that no competing interest exists.

\section{References}

1. Senapati S, Wang F, Ord T, Coutifaris C, Feng R, Mainigi M. Superovulation alters the expression of endometrial genes critical to tissue remodeling and placentation. J Assist Reprod Genet. 2018; 35: 1799-808.

2. Guillomot M, Campion E, Prezelin A, Sandra O, Hue I, Le Bourhis D, et al. Spatial and temporal changes of decorin, type I collagen and fibronectin expression in normal and clone bovine placenta. Placenta. 2014; 35: 737-47.

3. Armant DR. Blastocysts don't go it alone. Extrinsic signals fine-tune the intrinsic developmental program of trophoblast cells. Dev Biol. 2005; 280: $260-80$.

4. Nagy N, Barad C, Hotta R, Bhave S, Arciero E, Dora D, et al. Collagen 18 and agrin are secreted by neural crest cells to remodel their microenvironment and regulate their migration during enteric nervous system development. Development. 2018; 145 .

5. Haronen H, Zainul Z, Tu H, Naumenko N, Sormunen R, Miinalainen I, et al. Collagen XIII secures pre- and postsynaptic integrity of the neuromuscular synapse. Hum Mol Genet. 2017; 26: 2076-90.

6. Sorushanova A, Delgado LM, Wu Z, Shologu N, Kshirsagar A, Raghunath R, et al. The Collagen Suprafamily: From Biosynthesis to Advanced Biomaterial Development. Adv Mater. 2019; 31: e1801651.

7. Ricard-Blum S. The Collagen Family. Cold Spring Harbor Perspectives in Biology. 2010; 3: a004978-a.

8. Cohen M, Meisser A, Bischof P. Metalloproteinases and Human Placental Invasiveness. Placenta. 2006; 27: 783-93.

9. Lin C, He H, Cui N, Ren Z, Zhu M, Khalil RA. Decreased uterine vascularization and uterine arterial expansive remodeling with reduced matrix metalloproteinase-2 and -9 in hypertensive pregnancy. Am J Physiol Heart Circ Physiol. 2020; 318: H165-h80.

10. Oefner CM, Sharkey A, Gardner L, Critchley H, Oyen M, Moffett A. Collagen type IV at the fetal-maternal interface. Placenta. 2015; 36: 59-68.

11. Fu Q, Sun $Y$, Tao $Y$, Piao H, Wang X, Luan $X$, et al. Involvement of the JAK-STAT pathway in collagen regulation of decidual NK cells. Am J Reprod Immunol. 2017; 78

12. Fu Q, Tao Y, Piao H, Du MR, Li DJ. Trophoblasts and decidual stromal cells regulate decidual NK cell functions via interaction between collagen and LAIR-1. Am J Reprod Immunol. 2014; 71: 368-78.

13. Cutting GR, Kazazian HH, Jr., Antonarakis SE, Killen PD, Yamada Y, Francomano CA. Macrorestriction mapping of COL4A1 and COL4A2 collagen genes on human chromosome 13q34. Genomics. 1988; 3: 256-63.

14. Momota R, Sugimoto $M$, Oohashi $T$, Kigasawa $K$, Yoshioka H, Ninomiya $Y$. Two genes, COL4A3 and COL4A4 coding for the human alpha3(IV) and alpha4(IV) collagen chains are arranged head-to-head on chromosome $2 \mathrm{q} 36$. FEBS Lett. 1998; 424: 11-6.

15. Sugimoto $\mathrm{M}$, Oohashi T, Ninomiya $\mathrm{Y}$. The genes COL4A5 and COL4A6, coding for basement membrane collagen chains alpha 5(IV) and alpha 6(IV), are located head-to-head in close proximity on human chromosome Xq22 and COL4A6 is transcribed from two alternative promoters. Proc Natl Acad Sci U S A. 1994; 91: 11679-83.

16. Gelse K, Poschl E, Aigner T. Collagens--structure, function, and biosynthesis. Adv Drug Deliv Rev. 2003; 55: 1531-46.

17. Heino J. The collagen family members as cell adhesion proteins. Bioessays. 2007; 29: 1001-10.

18. Cui N, Hu M, Khalil RA. Biochemical and Biological Attributes of Matrix Metalloproteinases. Prog Mol Biol Transl Sci. 2017; 147: 1-73.

19. Kapoor C, Vaidya S, Wadhwan V, Kaur G, Pathak A. Seesaw of matrix metalloproteinases (MMPs). J Cancer Res Ther. 2016; 12: 28-35.

20. Rodriguez-Pinon M, Casuriaga D, Genovese P, Garcia-Barcelo G, Alcaide F, Bielli A. Collagen, glycosaminoglycans and matrix metalloproteinase-2 and metalloproteinase-9 in the cervix of the ewe during prepubertal development. Anat Histol Embryol. 2019: 48: 306-14.
21. Xiong XY, Liu Y, Shan LT, Xu YQ, Liang J, Lai YH, et al. Evaluation of collagen mixture on promoting skin wound healing in zebrafish caused by acetic acid administration. Biochem Biophys Res Commun. 2018; 505: 516-22.

22. Kehlet SN, Manon-Jensen T, Sun S, Brix S, Leeming DJ, Karsdal MA, et al. A fragment of SPARC reflecting increased collagen affinity shows pathological relevance in lung cancer - implications of a new collagen chaperone function of SPARC. Cancer Biol Ther. 2018; 19: 904-12.

23. Huang G, Ge G, Izzi V, Greenspan DS. alpha3 Chains of type V collagen regulate breast tumour growth via glypican-1. Nat Commun. 2017; 8: 14351

24. Zhao HY, Zhang ZX. The research process of collagen and its receptor. Int J Immunol 2010; 33: 420-2.

25. Ricard-Blum S, Vallet SD. Matricryptins Network with Matricellular Receptors at the Surface of Endothelial and Tumor Cells. Front Pharmacol. 2016; 7: 11.

26. Goldberga I, Li R, Duer MJ. Collagen Structure-Function Relationships from Solid-State NMR Spectroscopy. Acc Chem Res. 2018; 51: 1621-9.

27. Akins ML, Luby-Phelps K, Bank RA, Mahendroo M. Cervical softening during pregnancy: regulated changes in collagen cross-linking and composition of matricellular proteins in the mouse. Biol Reprod. 2011; 84: 1053-62.

28. Skopinska-Wisniewska J, Kuderko J, Bajek A, Maj M, Sionkowska A, Ziegler-Borowska M. Collagen/elastin hydrogels cross-linked by squaric acid. Mater Sci Eng C Mater Biol Appl. 2016; 60: 100-8.

29. Canty EG. Procollagen trafficking, processing and fibrillogenesis. Journal of Cell Science. 2005; 118: 1341-53.

30. Kisling A, Lust RM, Katwa LC. What is the role of peptide fragments of collagen I and IV in health and disease? Life Sci. 2019; 228: 30-4.

31. Brown SR, Cleveland EM, Deeken CR, Huitron SS, Aluka KJ, Davis KG. Type I/type III collagen ratio associated with diverticulitis of the colon in young patients. I Surg Res. 2017; 207: 229-34.

32. Lo CM, Wang HB, Dembo M, Wang YL. Cell movement is guided by the rigidity of the substrate. Biophys J. 2000; 79: 144-52.

33. Schlunck $G$, Han $H$, Wecker $T$, Kampik $D$, Meyer-ter-Vehn $T$, Grehn $F$. Substrate rigidity modulates cell matrix interactions and protein expression in human trabecular meshwork cells. Invest Ophthalmol Vis Sci. 2008; 49: 262-9.

34. Damsky $\mathrm{CH}$, Fitzgerald ML, Fisher SJ. Distribution patterns of extracellular matrix components and adhesion receptors are intricately modulated during first trimester cytotrophoblast differentiation along the invasive pathway, in vivo. Journal of Clinical Investigation. 1992; 89: 210-22.

35. Apps R, Sharkey A, Gardner L, Male V, Trotter M, Miller N, et al. Genome-wide expression profile of first trimester villous and extravillous human trophoblast cells. Placenta. 2011; 32: 33-43.

36. Zheng X, Liu W, Xiang J, Liu P, Ke M, Wang B, et al. Collagen I promotes hepatocellular carcinoma cell proliferation by regulating integrin beta1/FAK signaling pathway in nonalcoholic fatty liver. Oncotarget. 2017; 8: 95586-95.

37. Bojic-Trbojevic Z, Jovanovic Krivokuca M, Stefanoska I, Kolundzic N, Vilotic A, Kadoya T, et al. Integrin beta1 is bound to galectin-1 in human trophoblast. J Biochem. 2018; 163: 39-50.

38. Li MQ, Hou XF, Shao J, Tang CL, Li DJ. The DSCs-expressed CD82 controls the invasiveness of trophoblast cells via integrinbeta1/MAPK/MAPK3/1 signaling pathway in human first-trimester pregnancy. Biol Reprod. 2010; 82: 968-79.

39. Vinketova K, Mourdjeva M, Oreshkova T. Human Decidual Stromal Cells as a Component of the Implantation Niche and a Modulator of Maternal Immunity. J Pregnancy. 2016; 2016: 8689436.

40. Spiess K, Zorn TM. Collagen types I, III, and V constitute the thick collagen fibrils of the mouse decidua. Microsc Res Tech. 2007; 70: 18-25.

41. Spiess K, Teodoro WR, Zorn TM. Distribution of collagen types I, III, and V in pregnant mouse endometrium. Connect Tissue Res. 2007; 48: 99-108.

42. Iwahashi $M$, Nakano $R$. Decreased type $V$ collagen expression in human decidual tissues of spontaneous abortion during early pregnancy. J Clin Pathol. 1998; 51: 44-6

43. Iwahashi M, Muragaki Y, Ooshima A, Nakano R. Decreased type IV collagen expression by human decidual tissues in spontaneous abortion. J Clin Endocrinol Metab. 1996; 81: 2925-9.

44. Pollheimer J, Bauer S, Huber A, Husslein P, Aplin JD, Knofler M. Expression pattern of collagen XVIII and its cleavage product, the angiogenesis inhibitor endostatin, at the fetal-maternal interface. Placenta. 2004; 25 : 770-9.

45. Yong HEJ, Murthi P, Wong MH, Kalionis B, Brennecke SP, Keogh RJ. Anti-angiogenic collagen fragment arresten is increased from 16 weeks' gestation in pre-eclamptic plasma. Placenta. 2015; 36: 1300-9.

46. Munoz-Fernandez R, Prados A, Leno-Duran E, Blazquez A, Garcia-Fernandez JR, Ortiz-Ferron G, et al. Human decidual stromal cells secrete C-X-C motif chemokine 13, express B cell-activating factor and rescue B lymphocytes from apoptosis: distinctive characteristics of follicular dendritic cells. Hum Reprod. 2012; 27: 2775-84

47. $\mathrm{Du} \mathrm{MR}$, Wang $\mathrm{SC}, \mathrm{Li} \mathrm{DJ}$. The integrative roles of chemokines at the maternal-fetal interface in early pregnancy. Cell Mol Immunol. 2014; 11: $438-48$.

48. Lu H, Jin LP, Huang HL, Ha SY, Yang HL, Chang RQ, et al. Trophoblast-derived CXCL12 promotes CD56(bright) CD82(-) CD29(+) NK cell enrichment in the decidua. Am J Reprod Immunol. 2020; 83.

49. Saito S, Nishikawa K, Morii T, Narita N, Enomoto M, Ito A, et al. A study of CD45RO, CD45RA and CD29 antigen expression on human decidual T cells in an early stage of pregnancy. Immunol Lett. 1994; 40: 193-7.

50. Lee H, Zhang D, Wu J, Otterbein LE, Jin Y. Lung Epithelial Cell-Derived Microvesicles Regulate Macrophage Migration via 
MicroRNA-17/221-Induced Integrin beta1 Recycling. J Immunol. 2017; 199: 1453-64.

51. Oyen ML, Calvin SE, Landers DV. Premature rupture of the fetal membranes: Is the amnion the major determinant? American Journal of Obstetrics and Gynecology. 2006; 195: 510-5

52. Mi Y, Wang W, Lu J, Zhang C, Wang Y, Ying H, et al. Proteasome-mediated degradation of collagen III by cortisol in amnion fibroblasts. J Mol Endocrinol. 2018; 60: 45-54.

53. Malak TM, Ockleford CD, Bell SC, Dalgleish R, Bright N, Macvicar J. Confocal immunofluorescence localization of collagen types I, III, IV, V and VI and their ultrastructural organization in term human fetal membranes. Placenta. 1993; 14: 385-406.

54. Fortunato SJ, Menon R, Lombardi SJ. MMP/TIMP imbalance in amniotic fluid during PROM: an indirect support for endogenous pathway to membrane rupture. J Perinat Med. 1999; 27: 362-8.

55. Vadillo-Ortega F, Estrada-Gutierrez G. Role of matrix metalloproteinases in preterm labour. Bjog. 2005; 112 Suppl 1: 19-22.

56. Modesti A, Kalebic T, Scarpa S, Togo S, Grotendorst G, Liotta LA, et al. Type V collagen in human amnion is a $12 \mathrm{~nm}$ fibrillar component of the pericellular interstitium. Eur J Cell Biol. 1984; 35: 246-55.

57. Risteli L, von Koskull H, Autio-Harmainen H, Risteli J. Amniotic fluid laminin and type IV collagen in normal and pathological pregnancies. Clin Chim Acta. 1985; 147: 283-90.

58. Zuo G, Dong JX, Zhao FF, Chen Y. Expression of matrix metalloproteinase-9 and its substrate level in patients with premature rupture of membranes. J Obstet Gynaecol. 2017; 37: 441-5.

59. Zhou H, Kimura K, Orita T, Nishida T, Sonoda KH. Inhibition by female sex hormones of collagen degradation by corneal fibroblasts. Mol Vis. 2011; 17: 3415-22.

60. Montoya TI, Maldonado PA, Acevedo JF, Word RA. Effect of vaginal or systemic estrogen on dynamics of collagen assembly in the rat vaginal wall. Biol Reprod. 2015; 92: 43

61. Nallasamy S, Yoshida K, Akins M, Myers K, Iozzo R, Mahendroo M. Steroid Hormones Are Key Modulators of Tissue Mechanical Function via Regulation of Collagen and Elastic Fibers. Endocrinology. 2017; 158: 950-62.

62. Diao H, Aplin JD, Xiao S, Chun J, Li Z, Chen S, et al. Altered spatiotemporal expression of collagen types I, III, IV, and VI in Lpar3-deficient peri-implantation mouse uterus. Biol Reprod. 2011; 84: 255-65.

63. Taylor CT, Colgan SP. Regulation of immunity and inflammation by hypoxia in immunological niches. Nat Rev Immunol. 2017; 17: 774-85.

64. Semenza Gregg L. Hypoxia-Inducible Factors in Physiology and Medicine. Cell. 2012; 148: 399-408.

65. Zhao H, Kalish FS, Wong RJ, Stevenson DK. Hypoxia regulates placental angiogenesis via alternatively activated macrophages. Am J Reprod Immunol. 2018; 80: e12989.

66. James JL, Stone PR, Chamley LW. The regulation of trophoblast differentiation by oxygen in the first trimester of pregnancy. Hum Reprod Update. 2006; 12: $137-44$

67. Graham AM, Presnell JS. Hypoxia Inducible Factor (HIF) transcription factor family expansion, diversification, divergence and selection in eukaryotes. PLoS One. 2017; 12: e0179545.

68. Tong $\mathrm{W}$, Xue Q, Li Y, Zhang L. Maternal hypoxia alters matrix metalloproteinase expression patterns and causes cardiac remodeling in fetal and neonatal rats. Am J Physiol Heart Circ Physiol. 2011; 301: H2113-21.

69. Lambertini E, Penolazzi L, Angelozzi M, Bergamin LS, Manferdini C, Vieceli Dalla Sega F, et al. Hypoxia Preconditioning of Human MSCs: a Direct Evidence of HIF-1alpha and Collagen Type XV Correlation. Cell Physiol Biochem. 2018; 51: 2237-49.

70. Corpechot C, Barbu V, Wendum D, Kinnman N, Rey C, Poupon R, et al. Hypoxia-induced VEGF and collagen I expressions are associated with angiogenesis and fibrogenesis in experimental cirrhosis. Hepatology. 2002; 35: $1010-21$

71. Novo E, Cannito S, Zamara E, Valfre di Bonzo L, Caligiuri A, Cravanzola C, et al. Proangiogenic cytokines as hypoxia-dependent factors stimulating migration of human hepatic stellate cells. Am J Pathol. 2007; 170: 1942-53.

72. Hu Y, Hu D, Yu H, Xu W, Fu R. Hypoxiainducible factor 1alpha and ROCK1 regulate proliferation and collagen synthesis in hepatic stellate cells under hypoxia. Mol Med Rep. 2018; 18: 3997-4003.

73. Ortega MA, Asunsolo A, Alvarez-Rocha MJ, Romero B, De Leon-Luis I, Alvarez-Mon $\mathrm{M}$, et al. Remodelling of collagen fibres in the placentas of women with venous insufficiency during pregnancy. Histol Histopathol. 2018; 33. 567-76.

74. Shi JW, Yang HL, Fan DX, Yang SL, Qiu XM, Wang Y, et al. The role of CXC chemokine ligand 16 in physiological and pathological pregnancies. Am J Reprod Immunol. 2020: e13223.

75. Abbas Y, Carnicer-Lombarte A, Gardner L, Thomas J, Brosens JJ, Moffett A, et al. Tissue stiffness at the human maternal-fetal interface. Hum Reprod. 2019; 34: 1999-2008

76. Kafi MA, Aktar MK, Phanny Y, Todo M. Adhesion, proliferation and differentiation of human mesenchymal stem cell on chitosan/collagen composite scaffold. J Mater Sci Mater Med. 2019; 30: 131.

77. Ogata R. Type IV collagen and laminin enhance the motility, adhesion, and proliferation of hepatoma cells. Kurume Med J. 1998; 45: 11-20.
78. Vaniotis G, Rayes RF, Qi S, Milette S, Wang N, Perrino S, et al. Collagen IV-conveyed signals can regulate chemokine production and promote liver metastasis. Oncogene. 2018; 37: 3790-805.

79. Miyake M, Hori S, Morizawa Y, Tatsumi Y, Toritsuka M, Ohnishi S, et al. Collagen type IV alpha 1 (COL4A1) and collagen type XIII alpha 1 (COL13A1) produced in cancer cells promote tumor budding at the invasion front in human urothelial carcinoma of the bladder. Oncotarget. 2017; 8: 36099-114.

80. Xu P, Wang Y, Piao Y, Bai S, Xiao Z, Jia Y, et al. Effects of matrix proteins on the expression of matrix metalloproteinase-2, -9 , and -14 and tissue inhibitors of metalloproteinases in human cytotrophoblast cells during the first trimester. Biol Reprod. 2001; 65: 240-6.

81. Makareeva E, Han S, Vera JC, Sackett DL, Holmbeck K, Phillips CL, et al. Carcinomas contain a matrix metalloproteinase-resistant isoform of type I collagen exerting selective support to invasion. Cancer Res. 2010; 70: 4366-74.

82. Ren Z, Cui N, Zhu M, Khalil RA. Placental growth factor reverses decreased vascular and uteroplacental MMP-2 and MMP-9 and increased MMP-1 and MMP-7 and collagen types I and IV in hypertensive pregnancy. Am J Physiol Heart Circ Physiol. 2018; 315: H33-H47.

83. Zhang XB, Yang YY, Zeng Y, Zeng HQ, Fu BB, Ko CY, et al. Anti-tumor effect of endostatin in a sleep-apnea mouse model with tumor. Clinical and Translational Oncology. 2018; 21: 572-81.

84. Hu P, Ma L, Wu ZQ, Zheng GY, Li JT. Effect of endostatin on proliferation, invasion and epithelial-mesenchymal transition of basal cell carcinoma cell A431. Eur Rev Med Pharmacol Sci. 2019. 23: 877-84.

85. Brassart-Pasco S, Senechal K, Thevenard J, Ramont L, Devy J, Di Stefano L, et al. Tetrastatin, the NC1 domain of the alpha4(IV) collagen chain: a novel potent anti-tumor matrikine. PLoS One. 2012; 7: e29587.

86. Pollheimer J, Husslein P, Knofler M. Invasive trophoblasts generate regulatory collagen XVIII cleavage products. Placenta. 2005; 26 Suppl A: S42-5.

87. Zhou Y, Fisher SJ, Janatpour M, Genbacev O, Dejana E, Wheelock M, et al. Human cytotrophoblasts adopt a vascular phenotype as they differentiate. A strategy for successful endovascular invasion? J Clin Invest. 1997; 99: 2139-51.

88. Maeshima Y, Colorado PC, Kalluri R. Two RGD-independent alpha vbeta 3 integrin binding sites on tumstatin regulate distinct anti-tumor properties. J Biol Chem. 2000; 275: 23745-50.

89. Sinai Talaulikar V, Kronenberger K, Bax BE, Moss R, Manyonda I. Differences in collagen ultrastructure of human first trimester decidua basalis and parietalis: implications for trophoblastic invasion of the placental bed. J Obstet Gynaecol Res. 2014; 40: 80-8.

90. Tong M, Abrahams VM. Immunology of the Placenta. Obstet Gynecol Clin North Am. 2020; 47: 49-63.

91. Rygiel TP, Stolte EH, de Ruiter T, van de Weijer ML, Meyaard L. Tumor-expressed collagens can modulate immune cell function through the inhibitory collagen receptor LAIR-1. Mol Immunol. 2011; 49: 402-6.

92. Lv S, Lu C, Li M, Wu M, Wang $\mathrm{O}$, Wang $\mathrm{X}$, et al. The dynamic changes in myocardial collagen metabolism in experimental autoimmune myocarditis rats. Hellenic J Cardiol. 2018; 59: 234-7.

93. Sojka DK, Yang L, Yokoyama WM. Uterine Natural Killer Cells. Front Immunol. 2019; 10: 960.

94. Sojka DK, Yang L, Yokoyama WM. Uterine natural killer cells: To protect and to nurture. Birth Defects Res. 2018; 110: 1531-8.

95. Foy M, Anezo O, Saule S, Planque N. PRL-3/PTP4A3 phosphatase regulates integrin beta1 in adhesion structures during migration of human ocular melanoma cells. Exp Cell Res. 2017; 353: 88-99.

96. Faroog SM, Ashour HM. Type II collagen induces peripheral tolerance in $\mathrm{BALB} / \mathrm{c}$ mice via the generation of CD8+ T regulatory cells. PLoS One. 2012; 7: e48635.

97. Furuzawa-Carballeda J, Macip-Rodriguez P, Galindo-Feria AS, Cruz-Robles D, Soto-Abraham V, Escobar-Hernandez S, et al. Polymerized-type I collagen induces upregulation of Foxp3-expressing CD4 regulatory $\mathrm{T}$ cells and downregulation of IL-17-producing $\mathrm{CD} 4(+) \mathrm{T}$ cells (Th17) cells in collagen-induced arthritis. Clin Dev Immunol. 2012; 2012: 618608.

98. Doncarli A, Stasiuk LM, Fournier C, Abehsira-Amar O. Conversion in vivo from an early dominant Th0/Th1 response to a Th2 phenotype during the development of collagen-induced arthritis. Eur J Immunol. 1997; 27: 1451-8.

99. Wang $\mathrm{H}, \mathrm{He} \mathrm{M}$, Hou $\mathrm{Y}$, Chen $\mathrm{S}$, Zhang $\mathrm{X}$, Zhang $\mathrm{M}$, et al. Role of decidual CD14(+) macrophages in the homeostasis of maternal-fetal interface and the differentiation capacity of the cells during pregnancy and parturition. Placenta. 2016; 38: 76-83.

100. Shapouri-Moghaddam A, Mohammadian S, Vazini H, Taghadosi M, Esmaeili SA, Mardani F, et al. Macrophage plasticity, polarization, and function in health and disease. J Cell Physiol. 2018; 233: 6425-40.

101. Chen P, Cescon M, Zuccolotto G, Nobbio L, Colombelli C, Filaferro M, et al. Collagen VI regulates peripheral nerve regeneration by modulating macrophage recruitment and polarization. Acta Neuropathol. 2015; 129: 97-113.

102. Lv D, Zhou L, Zheng X, Hu Y. Sustained release of collagen VI potentiates sciatic nerve regeneration by modulating macrophage phenotype. Eur J Neurosci. 2017; 45: 1258-67.

103. Rizov M, Andreeva P, Dimova I. Molecular regulation and role of angiogenesis in reproduction. Taiwan J Obstet Gynecol. 2017; 56: 127-32.

104. Meagher MJ, Weiss-Bilka HE, Best ME, Boerckel JD, Wagner DR, Roeder RK. Acellular hydroxyapatite-collagen scaffolds support angiogenesis and osteogenic gene expression in an ectopic murine model: Effects of hydroxyapatite volume fraction. J Biomed Mater Res A. 2016; 104: 2178-88. 
105. Chen Y, Chen S, Kawazoe N, Chen G. Promoted Angiogenesis and Osteogenesis by Dexamethasone-loaded Calcium Phosphate Nanoparticles/Collagen Composite Scaffolds with Microgroove Networks. Scientific Reports. 2018; 8.

106. Minor AJ, Coulombe KLK. Engineering a collagen matrix for cell-instructive regenerative angiogenesis. J Biomed Mater Res B Appl Biomater. 2020.

107. Mulholland J, Aplin JD, Ayad S, Hong L, Glasser SR. Loss of collagen type VI from rat endometrial stroma during decidualization. Biol Reprod. 1992; 46: 1136-43.

108. Petitclerc E, Boutaud A, Prestayko A, Xu J, Sado Y, Ninomiya Y, et al. New functions for non-collagenous domains of human collagen type IV. Novel integrin ligands inhibiting angiogenesis and tumor growth in vivo. J Biol Chem. 2000; 275: 8051-61.

109. Colorado PC, Torre A, Kamphaus G, Maeshima Y, Hopfer H, Takahashi K, et al. Anti-angiogenic cues from vascular basement membrane collagen. Cancer Res. 2000; 60: 2520-6.

110. Kamphaus GD, Colorado PC, Panka DJ, Hopfer H, Ramchandran R, Torre A, et al. Canstatin, a novel matrix-derived inhibitor of angiogenesis and tumor growth. J Biol Chem. 2000; 275: 1209-15.

111. Shang D, Zheng Q, Song Z, Li Y, Wang X, Guo X. Eukaryotic expression of human arresten gene and its effect on the proliferation of vascular smooth muscle cells. J Huazhong Univ Sci Technolog Med Sci. 2006; 26: 202-5.

112. Reiss-Pistilli ML, Schuppan D, Barroso MM, Assuncao-Miranda I, Farias S, Lery $\mathrm{L}$, et al. An extracellular proteasome releases endostatin from human collagen XVIII. Angiogenesis. 2017; 20: 125-37.

113. O'Reilly MS, Boehm T, Shing Y, Fukai N, Vasios G, Lane WS, et al. Endostatin: an endogenous inhibitor of angiogenesis and tumor growth. Cell. 1997; 88: 277-85.

114. Wang S, Lu XA, Liu P, Fu Y, Jia L, Zhan S, et al. Endostatin has ATPase activity, which mediates its antiangiogenic and antitumor activities. Mol Cancer Ther. 2015; 14: 1192-201.

115. Dhanabal M, Ramchandran R, Waterman MJ, Lu H, Knebelmann B, Segal M, et al. Endostatin induces endothelial cell apoptosis. J Biol Chem. 1999; 274: 11721-6.

116. Leppert PC. Anatomy and physiology of cervical ripening. Clin Obstet Gynecol. 1995; 38: 267-79

117. Read CP, Word RA, Ruscheinsky MA, Timmons BC, Mahendroo MS. Cervical remodeling during pregnancy and parturition: molecular characterization of the softening phase in mice. Reproduction. 2007; 134: 327-40.

118. Mahendroo M. Cervical remodeling in term and preterm birth: insights from an animal model. Reproduction. 2012; 143: 429-38.

119. Fonseca EB, Celik E, Parra M, Singh M, Nicolaides KH. Progesterone and the risk of preterm birth among women with a short cervix. N Engl J Med. 2007; 357: 462-9.

120. Rouse DJ, Caritis SN, Peaceman AM, Sciscione A, Thom EA, Spong CY, et al. A trial of 17 alpha-hydroxyprogesterone caproate to prevent prematurity in twins. N Engl J Med. 2007; 357: 454-61.

121. Yellon SM, Burns AE, See JL, Lechuga TJ, Kirby MA. Progesterone withdrawal promotes remodeling processes in the nonpregnant mouse cervix. Biol Reprod. 2009; 81: 1-6.

122. Yellon SM, Ebner CA, Elovitz MA. Medroxyprogesterone Acetate Modulates Remodeling, Immune Cell Census, and Nerve Fibers in the Cervix of a Mouse Model for Inflammation-induced Preterm Birth. Reproductive Sciences. 2009; 16: $257-64$.

123. Saravelos $\mathrm{SH}, \mathrm{Li}$ TC. Unexplained recurrent miscarriage: how can we explain it? Hum Reprod. 2012; 27: 1882-6.

124. Li P, Wu HL, Dong BH. Relationship between TLR4 and CCL2 expression and recurrent spontaneous abortion. Genet Mol Res. 2016; 15.

125. Albaghdadi AJ, Kan FW. Endometrial receptivity defects and impaired implantation in diabetic NOD mice. Biol Reprod. 2012; 87: 30.

126. Favaro RR, Salgado RM, Covarrubias AC, Bruni F, Lima C, Fortes ZB, et al. Long-term type 1 diabetes impairs decidualization and extracellular matrix remodeling during early embryonic development in mice. Placenta. 2013; 34: 1128-35.

127. Dixon A, Maric C. 17beta-Estradiol attenuates diabetic kidney disease by regulating extracellular matrix and transforming growth factor-beta protein expression and signaling. Am J Physiol Renal Physiol. 2007; 293: F1678-90.

128. White CA, Robb L, Salamonsen LA. Uterine extracellular matrix components are altered during defective decidualization in interleukin-11 receptor alpha deficient mice. Reprod Biol Endocrinol. 2004; 2 : 76

129. Report of the National High Blood Pressure Education Program Working Group on High Blood Pressure in Pregnancy. Am J Obstet Gynecol. 2000; 183: S1-s22.

130. Li W, Cui N, Mazzuca MQ, Mata KM, Khalil RA. Increased vascular and uteroplacental matrix metalloproteinase- 1 and -7 levels and collagen type I deposition in hypertension in pregnancy: role of TNF-alpha. Am J Physiol Heart Circ Physiol. 2017; 313: H491-h507.

131. Li W, Mata KM, Mazzuca MQ, Khalil RA. Altered matrix metalloproteinase-2 and -9 expression/activity links placental ischemia and anti-angiogenic sFlt-1 to uteroplacental and vascular remodeling and collagen deposition in hypertensive pregnancy. Biochem Pharmacol. 2014; 89: 370-85.

132. Johnson MP, Fitzpatrick E, Dyer TD, Jowett JB, Brennecke SP, Blangero J, et al. Identification of two novel quantitative trait loci for pre-eclampsia susceptibility on chromosomes $5 \mathrm{q}$ and $13 \mathrm{q}$ using a variance components-based linkage approach. Mol Hum Reprod. 2007; 13: 61-7.
133. Yong HE, Murthi $\mathrm{P}$, Borg A, Kalionis B, Moses EK, Brennecke SP, et al Increased decidual mRNA expression levels of candidate maternal pre-eclampsia susceptibility genes are associated with clinical severity. Placenta. 2014; 35: 117-24.

134. Ducray JF, Naicker T, Moodley J. Pilot study of comparative placental morphometry in pre-eclamptic and normotensive pregnancies suggests possible maladaptations of the fetal component of the placenta. Eur J Obstet Gynecol Reprod Biol. 2011; 156: 29-34.

135. Devisme L, Merlot B, Ego A, Houfflin-Debarge V, Deruelle P, Subtil D. A case-control study of placental lesions associated with pre-eclampsia. Int J Gynaecol Obstet. 2013; 120: 165-8.

136. Ohmaru-Nakanishi T, Asanoma K, Fujikawa M, Fujita Y, Yagi H, Onoyama I, et al. Fibrosis in Preeclamptic Placentas Is Associated with Stromal Fibroblasts Activated by the Transforming Growth Factor-beta1 Signaling Pathway. Am J Pathol. 2018; 188: 683-95.

137. Lei H, Kalluri R, Furth EE, Baker AH, Strauss JF, 3rd. Rat amnion type IV collagen composition and metabolism: implications for membrane breakdown. Biol Reprod. 1999; 60: 176-82.

138. Kumar D, Moore RM, Mercer BM, Mansour JM, Redline RW, Moore JJ. The physiology of fetal membrane weakening and rupture: Insights gained from the determination of physical properties revisited. Placenta. 2016; 42: 59-73.

139. Skinner SJ, Campos GA, Liggins GC. Collagen content of human amniotic membranes: effect of gestation length and premature rupture. Obstet Gynecol. 1981; 57 : 487-9.

140. Wang WS, Li WJ, Wang YW, Wang LY, Mi YB, Lu JW, et al. Involvement of serum amyloid A1 in the rupture of fetal membranes through induction of collagen I degradation. Clin Sci (Lond). 2019; 133: 515-30.

141. Yonemoto H, Young CB, Ross JT, Guilbert LL, Fairclough RJ, Olson DM. Changes in matrix metalloproteinase (MMP)-2 and MMP-9 in the fetal amnion and chorion during gestation and at term and preterm labor. Placenta. 2006; 27: 669-77.

142. Maymon E, Romero R, Pacora P, Gervasi MT, Edwin SS, Gomez R, et al. Matrilysin (matrix metalloproteinase 7) in parturition, premature rupture of membranes, and intrauterine infection. Am J Obstet Gynecol. 2000; 182: 1545-53.

143. Nishihara S, Someya A, Yonemoto H, Ota A, Itoh S, Nagaoka I, et al. Evaluation of the expression and enzyme activity of matrix metalloproteinase-7 in fetal membranes during premature rupture of membranes at term in humans. Reprod Sci. 2008; 15: 156-65.

144. Wang LY, Wang WS, Wang YW, Lu JW, Lu Y, Zhang CY, et al. Drastic induction of MMP-7 by cortisol in the human amnion: implications for membrane rupture at parturition. FASEB J. 2019; 33: 2770-81.

145. Alfaidy N, Li W, MacIntosh T, Yang K, Challis J. Late gestation increase in 11beta-hydroxysteroid dehydrogenase 1 expression in human fetal membranes: a novel intrauterine source of cortisol. J Clin Endocrinol Metab. 2003; 88: 5033-8.

146. Sun K, Myatt L. Enhancement of glucocorticoid-induced 11beta-hydroxysteroid dehydrogenase type 1 expression by proinflammatory cytokines in cultured human amnion fibroblasts. Endocrinology. 2003; 144: 5568-77.

147. Mi Y, Wang W, Zhang C, Liu C, Lu J, Li W, et al. Autophagic Degradation of Collagen $1 \mathrm{~A} 1$ by Cortisol in Human Amnion Fibroblasts. Endocrinology. 2017; 158: 1005-14

148. Fortunato SJ, Menon R, Lombardi SJ. Presence of four tissue inhibitors of matrix metalloproteinases (TIMP-1, $-2,-3$ and -4 ) in human fetal membranes. Am J Reprod Immunol. 1998; 40: 395-400.

149. Maymon E, Romero R, Pacora P, Gomez R, Mazor M, Edwin S, et al. A role for the $72 \mathrm{kDa}$ gelatinase (MMP-2) and its inhibitor (TIMP-2) in human parturition, premature rupture of membranes and intraamniotic infection. J Perinat Med. 2001; 29: 308-16.

150. Lanocha-Arendarczyk N, Baranowska-Bosiacka I, Gutowska I, Kolasa-Wolosiuk A, Kot K, Lanocha A, et al. The Activity of Matrix Metalloproteinases (MMP-2, MMP-9) and Their Tissue Inhibitors (TIMP-1, TIMP-3) in the Cerebral Cortex and Hippocampus in Experimental Acanthamoebiasis. Int J Mol Sci. 2018; 19.

151. Kittaka S, Hasegawa S, Ito Y, Ohbuchi N, Suzuki E, Kawano S, et al. Serum levels of matrix metalloproteinase-9 and tissue inhibitor of metalloproteinases-1 in human herpesvirus-6-infected infants with or without febrile seizures. Journal of Infection and Chemotherapy. 2014; 20: 716-21.

152. Zaga-Clavellina V, Garcia-Lopez G, Flores-Pliego A, Merchant-Larios H, Vadillo-Ortega F. In vitro secretion and activity profiles of matrix metalloproteinases, MMP-9 and MMP-2, in human term extra-placental membranes after exposure to Escherichia coli. Reprod Biol Endocrinol. 2011; 9: 13. 